241 HUMAN FETAL UMBILICAL BLOOD FLOW ESTIMATION $\mathrm{OB} / \mathrm{Gyn}$, Surgery, and Anesthesia, Phila., PA.

Fetal $(F)$ and placental $(P)$ oxygen consumption $\left(\mathrm{V}_{2}\right)$ were calculated using continuous indirect calorimetry in 6 awake gravidas not in labor at 38 wks gestation with 6 AGA fetuses undergoing elective cesarean steady state was judged by stability of minute ventilation, MV́O percent carbon dioxide in expired air. Readings were obtained 10 an before delivery, 5-10 min after cord clamping and 10-20 min after placental removal. Blood samples were obtained from umbilical vein $(\gamma)$ was obtained within $30 \mathrm{~min}$ of delivery. $\mathrm{MVO}_{2}$ decreased after cord clamping $\left(\mathrm{FVO}_{2}\right)$, and still further after placental removal $\left(\mathrm{PVO}_{2}\right)$. Fetal umbilical blood flow (f) was calculated from the Fick equation by solving

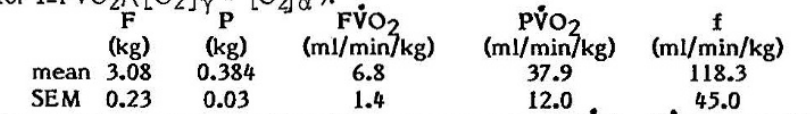

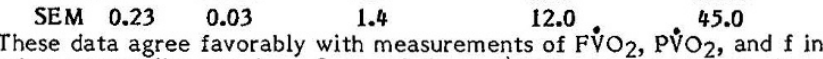
other mammalian species. Some of the variability in $f$ is accounted for by one baby whose $\mathrm{f}=338 \mathrm{ml} / \mathrm{min} / \mathrm{kg}, \mathrm{FVO}_{2}=13.0 \mathrm{ml} / \mathrm{min} / \mathrm{kg}$, and whose $\mathrm{F} / \mathrm{P}=11.0$. We speculate that babies attached to small placentas relative to their body size may have a higher metabolic rate during cesarean section than babies attached to large placentas relative to their body size.

\section{+ 242 INDUCTION OF CRYPTS FORMATION IN CULTURED FETAL} biologie cellulaire, Département de biochimie, Université de Sherbrooke, Sherbrooke, Québec, Canada (sponsored by M. R.-P1eszczynski).

In the fetal mouse small intestine villi differentiate during the last four days of gestation; crypts will differentiate only days of gestation contains a potent inducer of intestinal crypt formation (Anat. Rec. 205: 27-37, 1983). When an organic extract of RAF is added to Trowell T8 medium, well-developed villi differentiate and crypts are present after $48 \mathrm{~h}$ of culture, in duodenal explants taken from 15 -day mouse fetuses. The existence of a crypt differentiation factor (CDF) was then postuThe CDF activity in organic extract is well preserved after heating at $60^{\circ} \mathrm{C}$ or $100^{\circ} \mathrm{C}$ during $10 \mathrm{~min}$.: however after $1 \mathrm{~h}$ at $100^{\circ} \mathrm{C}$ the activity is considerably reduced. On reverse phase HPLC, CDF is poorly fractionated and shows a high polarily. With molecular seave chromatography by HPLC on Protein I $125 \mathrm{P}$ column, CDF is purified 10 times over original RAF dry weight. The apparent molecular weight of $\mathrm{CDF}$ is 13,000 daltons. When rat amiohoric na1 explants, crypts also differentiate: these fetal membranes tigation are needed in order to purify the CDF and to determine its chemical nature. "Supported by Grant No. MT6069 from the Medical Research Council of Canada." 241 BY APPLICATION OF THE BOHR PRINCIPLE. Duane $R$. Gutsche, (Spon. by M. Delivoria-Papadopoulos). Univ. of PA., Depts. of and artery $(\alpha)$ for oxygen content $\left[\mathrm{O}_{2}\right]$. A trimmed, drained P weight for $\mathrm{f}=\mathrm{FVO}_{2} /\left(\left[\mathrm{O}_{2}\right]_{\gamma}-\left[\mathrm{O}_{2}\right]_{\alpha}\right)$.

242 MOUSE DUODENUM. G. Bordeleau, F. Bouthilliex, J.-G. after birth. We have shown that rat amniotic fluid (RAF) at 19 tence of a crypt differentiation factor (CDF) was then postu-
late. We report here a partial characterization of this factor. could be responsible for the production of CDF. Further inves-

244

HYPOXIA, LUNG GROWTH AND THE SURFACTANT SYSTEM DURING ALVEOLARIZATION. D. Buchter, K. Franke, L. Brown, and G. Brumley, Department of Pediatrics, Emory University School of Medicine, Atlanta, GA Alveolarization in the rat occurs during the first 21 days and provides surface area proportional to oxygen needs. Lung size is known to increase in distance runners and persons living at altitude. Rat dams with $7-1$ day old pups (HR), were placed $0.12 \mathrm{O}_{x}$ in a recirculating chamber using $\mathrm{N}_{\mathrm{x}}$ to reduce $\mathrm{O}_{2}$ and soda lime to absorb $\mathrm{CO}_{2}$. Control dams and comparable litters of pups (CR) were raised in $0.21 \mathrm{O}_{2}$ under similar conditions. At $20-21$ days $\mathrm{HR}$ and $\mathrm{CR}$ pups were weighed, injected with $\left[{ }^{4} \mathrm{C}\right]$ methylcholine, and the lungs removed, weighed, and homogenized. A lamellar body (LB) fraction was derived by sucrose density centrifugation and LB disaturated phosphatidylcholine (LBPC) was extracted, quantitated, and the specific activity determined. HR pups were hyperpneic and runted significantly as compared to CR $(36.1 \mathrm{~g}$ vs $51.4 \mathrm{~g}, p<0.001)$, although $H R$ and $C R$ lung weights were not different $(1.41 \mathrm{~g}$ vs $1.38 \mathrm{~g})$ and the \% dry weights were different ( $1.41 \mathrm{~g}$ vs $1.38 \mathrm{~g}$ ) and the \% dry weights were
comparable (HR 21.0 vs CR 20.6). LW/BW however, was comparable (HR 21.0 vs CR 20.6). LW/BW however, was
significantly increased in HR (0.039 vs $0.028 \mathrm{p}<.005)$. $\mathrm{LBPC} / \mathrm{g}$ lung was comparable in HR and $\mathrm{CR}$ (209.1 vs 194.2). The accumulations of label in LBPC (dpm/ $\mathrm{mol} / \mathrm{min}$ ) as an index of synthesis was higher in HR (183.7 vs 291.9, p<.001). These data show decreased body growth but not lung growth in response to hypoxia. The increase in LBPC labelling suggest more rapid synthesis of surfactant lipid perhaps in response more rapid synth
to hyperpnea.

POSTNATAL GROWTH AND FATTY ACID SYNTHESIS IN

245 INSULIN-INDUCED MACROSOMIC RAT PUPS. Elizabeth A. Catlin, Chung-Ja Cha, William Oh, Brown Univ, Women \& Infants Hosp, Dept of Ped, Providence, RI

Fetal hyperinsulinemia results in neonatal macrosomia and enhanced lipogenesis. The purpose of this study was to determine whether these neonatal observations persist postnatally in this animal model. Fetal hyperinsulinemia was produced in SpragueDawley rats by injecting fetuses with 2 units of PZI insulin at 20.5 days gestation. Alternate pups in the same litter were injected with isovolemic saline (control). Following cesarean birth at term, the pups were nursed ad lib by foster mothers. Daily weights were obtained and at 15 days of age fatty acid contents and synthesis at 15 days of age fatty acid contents and synthesis (tritiated water technique) were measured. At birth insulin treated pups were $12 \%$ heavier than control $(5.88 \pm 0.15$ vs. $5.26 \pm 0.14 \mathrm{~g}, \mathrm{M} \pm$ SEM, $\mathrm{p}<.01)$. As shown in graphs, growth and growth velocity were enhanced during suckling period in insulin treated pups. FA contents of liver and muscle in insulin pups, $(62.6 \pm$ $5.7 \mu \mathrm{mole} / \mathrm{g}$ and $62.7 \pm 13.2 \mu \mathrm{mole} / \mathrm{g})$ were significanty littermates $(45.1 \pm 5.6 \mu \mathrm{mole} / \mathrm{g}$ and $30.2 \pm 4.7 \mu \mathrm{mole} / \mathrm{g}$, respectively). We conclude that: 1 . Fetal hyperin-

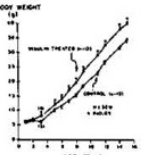
condition and may serve as a useful model for the study of childhood obesity; 2. Persistent enhancement of somatic growth in these pups was associated with higher lipid contents in liver and muscle indicating continuing anabolic effect.

THE INSULIN/GLUCAGON RATIO AFFECTS MITOCHONDRIAL ADE-

243 NINE NUCLEOTIDE ACCUMULATION AND PYRUVATE CARBOXYLA-

TION IN NEWBORN RABBIT LIVER. WiTliam A. Brennan, Jr.\& June R. Aprille. Tufts Univ., Dept. Biol., Medford, MA 02155.

We have shown that a rapid postnatal increase in hepatic mitochondrial adenine nucieotide content and the matrix ATP/ADP ratio activates pyruvate carboxylation (a matrix reaction) thereby stimulating gluconeogenesis in the newborn rabbit (Ped.Res. 1983, $17: 129)$. Here we examined the role of insulin and glucagon as initiating stimuli for this phenomenon. Manipulation of the insu1 in/glucagon ratio in vivo by insul in injection at birth delayed postnatal increases in mitochondrial adenine nucleotide content and pyruvate carboxylation ( 65 and $69 \%$ of controls respectively at 2 hrs after birth). Conversely, glucagon injection produced a supranormal increase in both mitochondrial adenine nucleotide content and pyruvate carboxylation (114 and $119 \%$ of control respectively at 2 hrs postnatal). In addition, insul in injection prevented, while glucagon enhanced the normal postnatal increase in the cellular ATP/ADP ratio ( 2 fold decrease and 1.3 fold increase respectively by $1 \mathrm{hr}$ after birth). These results show that a decreased insulin/glucagon ratio promotes the rapid movement of adenine nucleotides from the liver cytosol into the mitochondrial matrix. The increased matrix concentration of ATP stimulates pyruvate carboxylation, thereby activating gluconeogenesis during very early postnatal life. The results also suggest that persistent hypogiycemia in infants born to diabetic mothers may be due to a delay in the onset of postnatal gluconeogenesis that is secondary to a higher than normat insulin/glucagon ratio. (NIH HD 16936) Brown Univ, Women \& Infants Hosp, $\frac{\text { Chung-Ja M. Cha, William Oh, }}{\text { Dept of Ped, Providence, RI }}$ Growth rate and fatty acid (FA) metabolism were evaluated in the first $3 \frac{1}{2}$ days of life in rats as a function of degree of intrauterine growth retardation (IUGR) and of postnatal nutrition. IUGR (mild, $B W \leq 1$ SD and severe, $B W \leq 2$ SD) was produced by uterine artery ligation on 18 th day of gestation, and controls were sham operated. Food intake was manipulated by varying the litter size per dam; $n=16$ for underfeeding, $n=10$ for normal feeding and $n=4$ for overfeeding. The growth rate in the control pups was reduced by underfeeding while overfeeding and normal feeding resulted in the same rate. The mild IUGR responded the same way as in control. In severe IUGR group, the growth rate was similar regardless of the feeding protocol. The fatty acid content in carcass was reduced as a result of either prenatal or postnatal under(tritiated water technique). In liver and lung, there was no difference in FASR between controls and IUGR and feeding did not influence the rate; the fat content was lower in under fed control and in IUGR rats. In the brain, FASR of normal fed IUGR was marked1y higher and the rate almost doubled in underfed IUGR. This was accompanied by significantly less FA contents in both normal fed and under fed IUGR group. We ccnclude that postnatal undernutrition retards postnatal growth of normal and mildly affected IUGR rats, but no additional growth retardation was observed in the severely affected IUGR pups. The changes in fatty acid metabolism in various organs studied were c.msistent with the alterations in growth.
246 INTRAUTERINE GROWTH RETARDATION: EFFECTS OF nutrition in spite of a higher fatty acid synthesis rate (FASR) 